\title{
NEW ASPECTS OF EUROPEAN ROAD ACCESSIBILITY
}

\author{
GEZA TOTH* and AंRON KINCSES \\ Hungarian Central Statistical Office, Budapest, Hungary, \\ 1024 Budapest, Keleti Karoly ut 5-7., Hungary \\ E-mail: *geza.toth $\omega \mathrm{ksh} . h \mathrm{u}$
}

\begin{abstract}
The utilisation of accessibility potential models is widespread in geographical studies of transport. A problem emerges, however, when these models are applied in that their interpretations and results may result in some difficulties and ambiguity. In order to eliminate this problem, we have developed a method which is convenient for breaking down the accessibility potentials into four univocal elements. This article analyses the features of these factors and the interrelationships of their spatial development patterns by using the example of the EU NUTS3 regions.
\end{abstract}

Key words: accessibility potential; regional development, European Union

\section{INTRODUCTION}

The methods of accessibility modelling have a long history in scientific literature. The most widespread and most frequently used indicators in this area are accessibility potential models. Accessibility potential models (which are based on a gravitational analogy) have been widely used in urban and geographical studies since the 1940s, of which the most well-known are those of: Stewart (1947), Harris, (1954) Hansen (1959), Ingrảm (1971), Vickerman (1974), Keeble et al. (1988), Linneker and Spence (1992), Smith and Gibb (1993) Spence and Linneker (1994). After the disjoint, fully covered territorial division, the potential models assess the possibility of accessing the optionally encircled territories (i) separately in relation to all the other territories (n); within these territories, those of smaller mass and/or those that are more remote have a decreasing effect and vice versa (Rich 1980), (Geertman and van Eck 1995).

The general form of the accessibility potential model (1) is the following:

$$
A_{i}=\sum_{j} D \cdot F\left(d_{i j}\right)
$$

where:

$A_{i}$ is the accessibility of territory $i, D$ is the mass of territory $\mathrm{j}$ that is accessible from territory $i, d_{i j}$ is the general travel cost between territories $\mathrm{i}$ and $\mathrm{j}, F\left(d_{i j}\right)$ is the impedance function.

In accessibility studies, authors who use different accessibility potential models apply different impedance functions. The reason for applying an impedance function in socio-geographical studies is primarily because spatial separation hinders cooperation among the different regions, so it is worth quantifying in some way. The simplest 
application of the model is naturally the use of distances in air kilometres.

The main difference in the application of the accessibility potential model and the physical potential model is that, in contrast to physical space, social space, in an everyday sense, typically is not continuous but discrete. Socio-economic formations (e.g. settlements, towns) are generally concentrated at a given point of space, and their 'mass' can be connected to this point. As these mass points do not fill the space, it can be difficult to determine the potential value of any point of an encircled part of space (e.g. a country), which depends naturally on the effect of all the other points. (Tagai 2007). These mass points' spatial concentrations of differing extents induce potential surfaces that have different characteristics, a consequence of which is that the distance between the points, and thus the impedance function, can be described by different functions in the different analyses. This means that the formula of the impedance function used in analyses for different regions, territorial levels or for different numbers of mass points in the same territorial level is different.

Therefore several forms of the impedance function appear in accessibility studies. The models also take into consideration the distance between certain 'masses' in different ways. Several approaches are known in which the researchers apply the reciprocal of the distance or one of its powers (see among others Hansen 1959; Davidson 1977; Fortheringham 1982). Among them, the most 'everyday' solution is provided by those models that apply a linear impedance function (when determining the potential, distance is in the first power in the denominator), âs here we do not perform any mathematical modification on the duration and cost of access. In models that strongly insist on a gravitational analogy, due to the physical demonstration of the model, the second power of distance, duration and cost are always applied. This, however, is not a rule that cannot be broken; there may, therefore, in models based on gravitational analogy, be other power values as well. In this case, their role is only to quantify the probability of reaching the targets at different distances in the model.

Researchers use the models that apply the exponential impedance function in order essentially to specify this objective (Wilson 1971; Dalvi-Martin 1976; Martin and Dalvi 1976; Song 1996; Simma et al. 2001; Schürmann et al. 1997). Models applying the impedance function of Gauss (Ingram 1971; Guy 1983) or the log-logistic impedance function (Bewley and Fiebig 1988; Hilbers and Veroen 1993) are also known. In similar studies, exponential (see among others ESPON 2007) and linear (Gutierrez 2001) impedance functions are used in numerous cases. The present study-especially in the later parts - applied only the linear impedance function, as it was the most suitable for interpreting the results. It should be noted, however, that the connection between the specific GDP and the potentials received as a result, was by no means the strongest when the linear model was applied (Toth-Kincses 2007). However, as the chief aim was to present the methodological possibilities, this model was applied further on.

The overseas territories of France, Portugal and Spain were not included in this study, so the term amount or average of the EU27 regions covers the regions on the continent in the case of each variable. Furthermore, the work also did not deal with models that take into account competition (see among others Weibul1 1976; Knox 1978; Van Wee et al. 2001; Joseph-Bantock 1982; Fotheringham 1982).

\section{THE ACCESSIBILITY MODEL APPLIED}

In the course of applying the potential model, not only own strength, (i.e. the value of the so-called own potential of spatial units) can be expressed but, with the value of internal potential, the interaction between the masses was also taken into consideration. External potential can be demonstrated by taking into account the masses outside the territory observed. 
Accordingly, the total potential value is the sum of these three results.

The applied accessibility potential model (2) is the following:

$$
A_{i}=\frac{W_{i}}{d_{i}}+\sum_{i} W_{d_{i}}^{W_{i}}+\sum_{i} W_{i}
$$

Total potential $=$ own potential + + internal potential + external potential

where the value of the own potential of point $A_{i}$ is the quotient of $\mathrm{W}_{\mathrm{i}}$ the own mass of the given territorial unit (in this study the population value) and the distance data ordered to the territorial unit $d_{i i}$ (the simplest way to obtain this is the length of the radius of the circle equal to its territory).

The procedures used for calculating own potential differ in their criteria of how the radius is to be weighted. The role of a centre can be highlighted or reduced by the weighting of the radius. Nitsch used distance equal to the size of the radiation, which in his opinion is based closely on the value within the average range (Nitsch 2000). Several different approaches can be found in the literature (Rich 1980; Keeble et al. 1982; Redding and Venables 2001), but we considered that to be the most appropriate. In any case, we can state that the length greatly influences the result of the calculation.

When calculating the internal potential, the sum of the effects of the other spatial units involved in the analysis of the given spatial unit must be calculated.

The size of the effect depends on the mass of the other points and on their distance from the given spatial unit. The larger the mass of the spatial unit at a nearer distance in space, the higher its value.

The calculation of external potential is practically the same as that of internal potential, but here the effects of spatial units outside the examined territory are taken into account.

In the case of internal potential, 1,288 NUTS3 regions of the European Union were taken into account. In the case of external potential, the known territorial units of the EFTA countries, the candidate countries (Croatia, Turkey) as well as further (primarily Eastern) European countries were taken into account. When calculating external potential, either national data (e.g. Liechtenstein) or data broken down regionally (e.g. the oblasts in Russia) were used. The number of territorial units taken into account in relation to external potential was 251.

In connection with external potential, it should be noted that each point on the world can be considered as affecting the potentials of all the other points. This naturally does not mean that a researcher takes into account the data of all territorial units; due to practical reasons, the number of points and territorial units considered has to be reduced. On the other hand, each decision made by the researcher when choosing the boundaries of the territory examined can be considered to be partly arbitrary, and this is thought to be the central problem of all macroscopic models (Lukermann and Porter 1960, p 503). Despite the fact that accessibility indicators quantify their accessibility to points in other regions, the total territory examined must be adjusted so that accessibility conditions are influenced not only by the internal accessibility of the region, but also by the external points. Therefore, as long as it is possible, it is worth engaging in as broad an examination of territory as possible, where all the target territories that are relevant to this examination are taken into account. By trying to take into consideration the effects emanating from each country of Europe, in a geographical sense, for determining the potential of the EU27, we attempted to meet this objective.

In our research the concept of accessibility always means physical accessibility or, more precisely, access time in minutes. In the preparation of the stock of road network data, routes have been coupled with those speed limits that are relevant to the respective road category, and access times were determined for all route segments (for sections from crossing to crossing). In the case of ferry connections, our calculations were 
based upon a $10 \mathrm{~km} /$ hour speed limit. With regard to networks, we determined the minimum access time demand of optimal routes by using the ArcView Network Analyst programme among all the regional centres of Europe. This procedure is the equivalent of defining the optimal access route between two points on a graph, where the edges of the graph are route segments, and resistance data relating to the edges are the time data that is necessary for passing through.

This article primarily uses this methodological approach and as such is mainly focused on the modelling. This is why, although in the processes of EU27 transport has determining part of the rail, air and the maritime transport, their impact-although the calculations would have been altered significantly-were not included in the model. The dimensions of the analysis can be seen in Table 1. since improving accessibility improves the productivity and competitiveness of companies. When accessibility improves as a consequence of investment, the labour market is also affected by positive impulses, which results in a further improvement in competitiveness (Forslund and Johansson 1995). Thus, it was deemed worth examining the connection between accessibility potential and economic development.

The first examination attempted to ascertain whether a type of connection can be demonstrated between the GDP and the population potential of the 1,288 NUTS3 regions of the European Union.

It should be noted in connection with the analysis that the primary objective of accessibility models is to map the potential of movements between certain territorial units and thus to model the spatial fields of force. The probability of movement, however, does not

Table 1: Dimensions of the analysis

\begin{tabular}{ll}
\hline Dimension & Notes \\
\hline Source & In the analysis, accessibility is calculated and interpreted from each person's point of view, and \\
no differentiation is made between the social groups or the different travel targets of travellers. & The objective to be achieved is quantified by the population of the given NUTS3 region. \\
Objective & The territorial impedance function means in this case the theoretical accessibility times between \\
Resistance & Whe centres of the regions on public roads is in minutes. \\
Limits & according to the type of road. \\
Boundaries & When determining the territory examined, the boundaries of Europe were taken into account \\
in a geographical sense. & The analysis focuses primary on aspects of passenger transport. \\
Means of transport & The analysis calculated unimodal accessibility with respect to public roads. \\
Modality & The basic regional level of the research is NUTS3. \\
Regional level & The major objectives of the research are to model the centre-periphery differences in the EU27 \\
Equal chances & regions, and studying the resulting differences. \\
In the research, the population and the public road network on 1 January 2007 are taken into &
\end{tabular}

\section{THE ANALYSIS}

The starting point in this study, which is similar to that of other works (Geurs and Wee 2004), was that accessibility can be used as an economic indicator as well, mean movement by all means, and movement in itself is not evidence of development (or its absence does not necessarily mean underdevelopment).

By examining the strength of the connection with a simple regression function, it can be found that population potential accounts 
for $16.4 \%$ of the dispersion of GDP per capita in the NUTS3 regions of the European Union.

\section{THE PROBLEM OF BREAKING DOWN ACCESSIBILITY POTENTIAL INTO FACTORS}

Several analyses discuss the advantages and disadvantages of the accessibility potential model (Geurs and van Eck 2001; Geurs and Wee 2004). We, on our part, would have liked to deal primarily with the disadvantages of the model. In this respect, the authors cited above say the following: "Disadvantages of potential measures are related to more difficult interpretation and communicability; the measure is not easily interpreted and communicated as it combines land-use and transport elements, and weighs opportunities (according to the cost sensitivity function)." (Geurs and Wee 2004 p. 134) The reason for the problem is that accessibility potential models measure the effects of spatial structures, spatial division, the location of a certain spatial domain, and the size distribution of masses at the same time. The location of the spatial domain is essentially determined by the geographical location, which is somewhat modified by the level of accessibility (depending on the means of transport). This means that in the case of a certain potential value, it cannot be determined whether it is a consequence of the (settlement, regional) structure or the location of the mass sizes, or of the size of the region, or the effect of its own mass.

Thus the gravitational space of social masses should be imagined as an optional division of the space (settlement, microregional structure, etc.) and then a mass distribution on this division (like masses distributed to the given spatial structure as quanta or counters). The value of the potential at a given point is determined by the sum of these effects (internal potential and external potential) and the effects of own mass and own spatial size (own potential).
The effect of the potential that is derived only from the division of the territory at an optional point of space, briefly the spatial structure effect (5) is the value which would result if the mass were the same in each encircled territorial unit. The mass distribution effect (6) is the difference between the sum of the internal and external potential at an optional point of space and the value of the spatial structure effect on this point. The value of the total potential is also influenced by the size of the given region (in this case NUTS3 region). The effect of the size of the region is the value which would result if the mass were the same in each territorial unit (7). Subtracting this from its own potential (8), we get the value of the effect of its own mass (Kincses and Tóth 2011).

The connections described above are as follows:

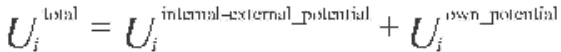

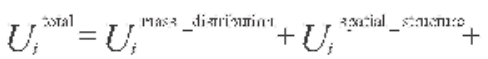

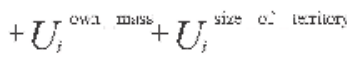

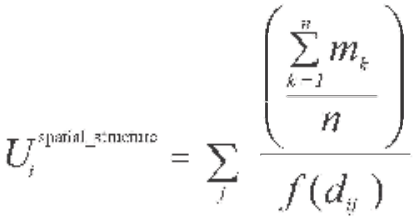

$$
\begin{aligned}
& U_{i}^{\text {rmiss listilibution }}=U_{i}^{\text {internal textemsil polemtial }}- \\
& -U_{j}^{\text {spritial stuctule }}
\end{aligned}
$$

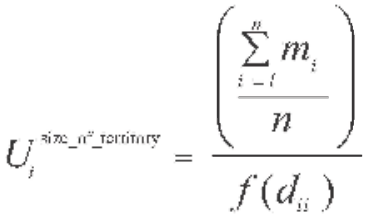

$$
U_{i}^{\text {Uxis: wisiss }}=U_{i}^{\text {vix. suleallial }}-U_{i}^{\text {sice of terrilary }}
$$

After breaking down the potential model, the situation based on the connection 
between these factors and GDP per capita is somewhat different. If we examine the connection between the potential models and the specific GDP with multivariable linear regression, as a result of the regression being applied to more than one variable, the determination coefficient is higher than in case of the basic model. Here, the value of $\mathrm{R}^{2}$ amounts to $31 \%$. The two factors determining the potential to the greatest extent (i.e. those having the highest standardized beta coefficient) are the territory of the given region and its own mass. It is important to highlight that the effect of spatial structure has the lowest, but not significant, standardized $\beta$ coefficient (Table 2).

Table 2: The connection between the factors of the accessibility potential model and GDP per capita, $\mathrm{R}^{2}$ and standardized $\beta$ coefficients

\begin{tabular}{lc}
\hline Model & $\begin{array}{l}\text { Standardized } \beta \\
\text { coefficients }\end{array}$ \\
\hline Adjusted R Square & 0.311 \\
Spatial structure & -0.017 \\
Mass distribution & -0.271 \\
Size of territory & 0.475 \\
Own mass & 0.345 \\
\hline
\end{tabular}

\section{CHARACTERISTICS OF THE FACTORS OF ACCESSIBILITY POTENTIAL}

According to our accessibility potential analyses, the most advanced region in the European Union is Paris, followed by SeineSaint-Denise and Val-de-Marne (In the following, for easier identification we name the home country and the NUTS2 regions of the NUTS 3 regions in brackets. Therefore the first is the Ile-de-France, FR) (Fig. 1). We can state in general that the central regions of France, Southern England, the Netherlands, Belgium, and the regions of Northern Italy are in the most advantageous situation. There is a continuous decrease in potential from the indicated core area to the peripheries. The lowest potential value is in
Värmland (Northern Sweden, SE), Lappi (Northern Finland, FI) and the Shetland Islands (the Highlands and Islands, UK). In some respects, our results confirm the Blue Banana spatial structural model (Brunet 1989), as well as its extension (Kuzmann 1992).

The effect of the spatial structure is positive in all cases, i.e. it always contributes to the total potential (Fig. 2). The effect of spatial structure was the highest in case of Oberhausen, Kreisfreie Stadt (Düsseldorf, DE); Frankenthal (Pfalz), Kreisfreie Stadt (Rheinhessen-Pfalz, DE) and the RheinPfalz-Kreis regions ((Rheinhessen-Pfalz, DE). By contrast, the lowest values were found in Pohjois-Pohjanmaa, Lappi (Northern Finland, FI), and in Cyprus.

The effect of spatial structure as a share of total potential is between 71 and $176 \%$. The former value is represented by Bucureşti (București-Ilfov, RO), while the latter is that of the Bamberg, Landkreis region (Oberfranken, DE). The effect of spatial structure is the most important factor in the total potential for each region.

The effect of the mass distribution-in contrast to the former factor-contributes negatively or positively to the total potential (Fig. 3). Of the 1,288 regions examined, in 1,224 the sign is negative; only the remaining 64 regions is it positive. The situation is the worst in those (primarily German) regions, which, by themselves, represent a significant mass, but the masses accessible from them are relatively low. These regions include: Rhein-Pfalz-Kreis (RheinhessenPfalz, DE), Bam-berg, Landkreis (Oberfranken, DE), Frankenthal (Pfalz), Kreisfreic Stadt (Rheinhessen-Pfalz, DE). On the other hand, in terms of mass distribution, the regions that are in the most advantageous situation are: West Inner London (Inner London, UK), Val-de-Marne, and Seine-Saint-Denis (Ile de France, FR).

The effect of mass distribution as a proportion of total potential is between -76 and $10 \%$. The former value is represented by the regions in Germany, with Bamberg, the Landkreis region (Oberfranken, DE) 


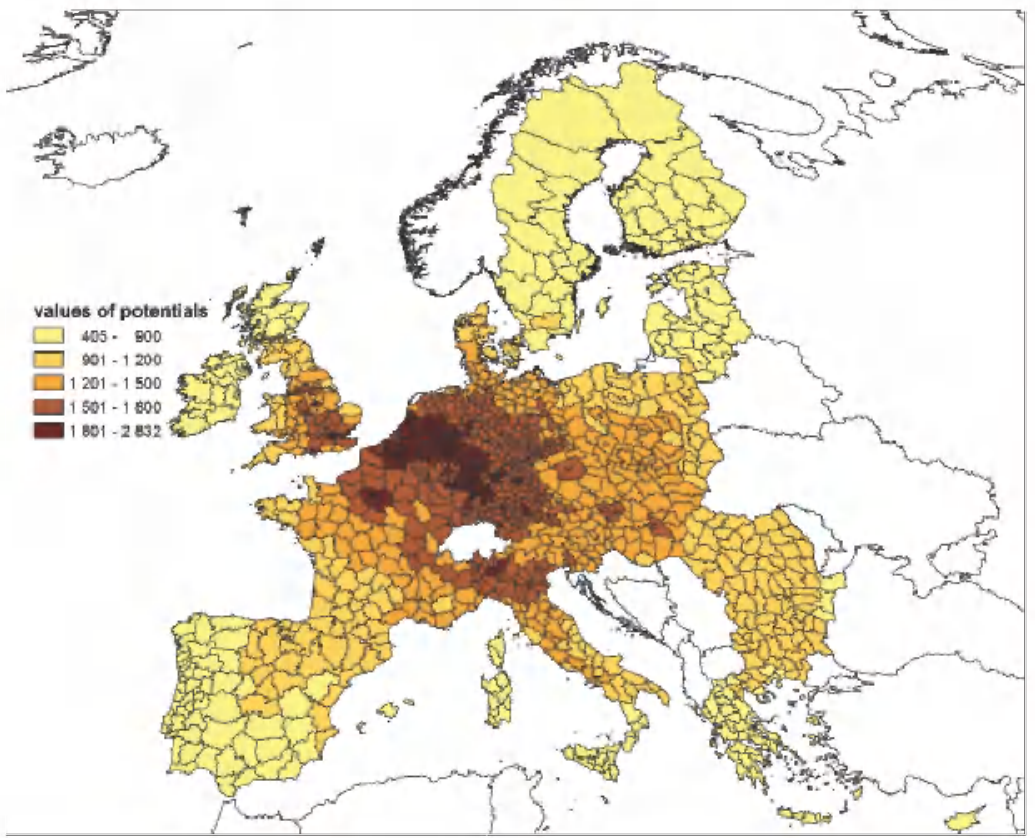

Figure 1. Population potential of the European Union's regions

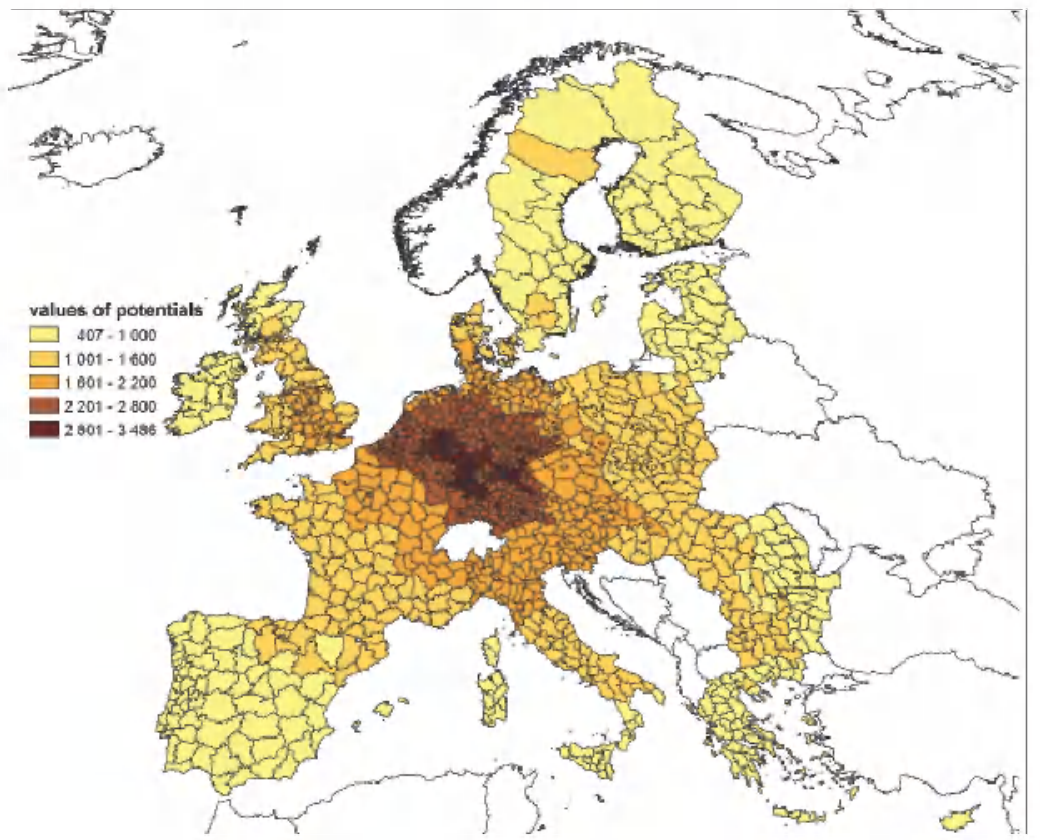

Figure 2. Role of spatial structure in population potential 
having the lowest scores, while in terms of the latter value we can point to the regions in Southern Europe, especially Guadalajara (Castile-La Mancha, ES) which is in the best situation.

The following two factors are parts of the own potential of the accessibility potential model. The first factor in this part is the size of territory (Fig. 4). As with when one calculates own potential in terms of the territory of the given region, the size of this factor changes according to the size of the territory of the region that is being considered. The sign of the size of the territory is always positive, and its value is higher the smaller the territory of the region is. The size of the factor refers primarily to urbanisation, since regions with a smaller area are mostly large cities. Accordingly, the maximum value of the territory size factor can be observed in Blackpool (Lancashire, UK), while the minimum value can be found in Norrbotten county (Upper Norrland, SE).

The share of the territory size factor in the total potential is between 0.4 and $14 \%$. The former value is represented by Norrbotten county (Upper Norrland, SE), while included in the latter are Stralsund, Kreisfreie Stadt (Mecklenburg-Vorpommern, DE). It should be emphasised that the share of the territory size factor in the total potential does not even reach $5 \%$ in nearly 1,200 regions.

Finally, the last factor is the own mass of the given region (Fig. 5). Its sign may also be negative or positive. Due to the method, the sign of regions more populated than the average is positive, while that of sparsely populated regions is negative. The share of the own mass factor in the total potentiāl is between -48 and $22 \%$. Included among the negative values are the regions of Stralsund, Kreisfreic Stadt, Greifswald, Kreisfreie Stadt and Bad Doberan (all three Mecklenburg-Vorpommern, DE), while included among the positive ones are the regions of București (București-Ilfov, RO) Athens (Attiki, GR) and Paris (Île de France, FR).

\section{COMPARISON OF THE ACCESSIBILITY AND DEVELOPMENT OF REGIONS}

In the comparison, we followed the method already used by ESPON (2003) as well as his classification. On this basis, regions can be classified according to four groups (Fig. 6). (Further analyses deal with the actual European trends of accessibility and their connection with regional development (ESPON 2009; Puga 2002; Spiekermann and Neubauer 2002; Spiekermann and Wegener 2006)

In the first group are those regions that are above the average in terms of both accessibility and development. Included in this group are the regions of Southern England, the Benelux, Southern Germany, Northern Italy and Northern France, which are considered to be the economic engines of the European Union. According to our study, the range of these regions is somewhat more significant than in the ESPON study in 2003. Slightly more than $30 \%$ of the total number of regions belong to this category.

The second group includes those regions whose accessibility is more advantageous than the EU27 average, but their level of development is below the average. Western Germany, some regions in those Central European countries that joined the EU in 2004, and some regions of Northern France are included in this group. $23 \%$ of the total number of regions belong to this second group.

The third group comprises those regions whose accessibility is below the average, but whose performance in terms of GDP per capita is above average. Primarily, the Swedish, Finnish and Irish regions belong to this category, but it âlso includes most of the régions of Northern Spain and the South and West of France, as well as some English, Scottish and Italian regions. Although many countries are included in this group, its size is the smallest among the four groups, as only $12 \%$ of the total number of regions fall within this category.

Finally, the fourth group is comprised of those regions which are below the aver- 


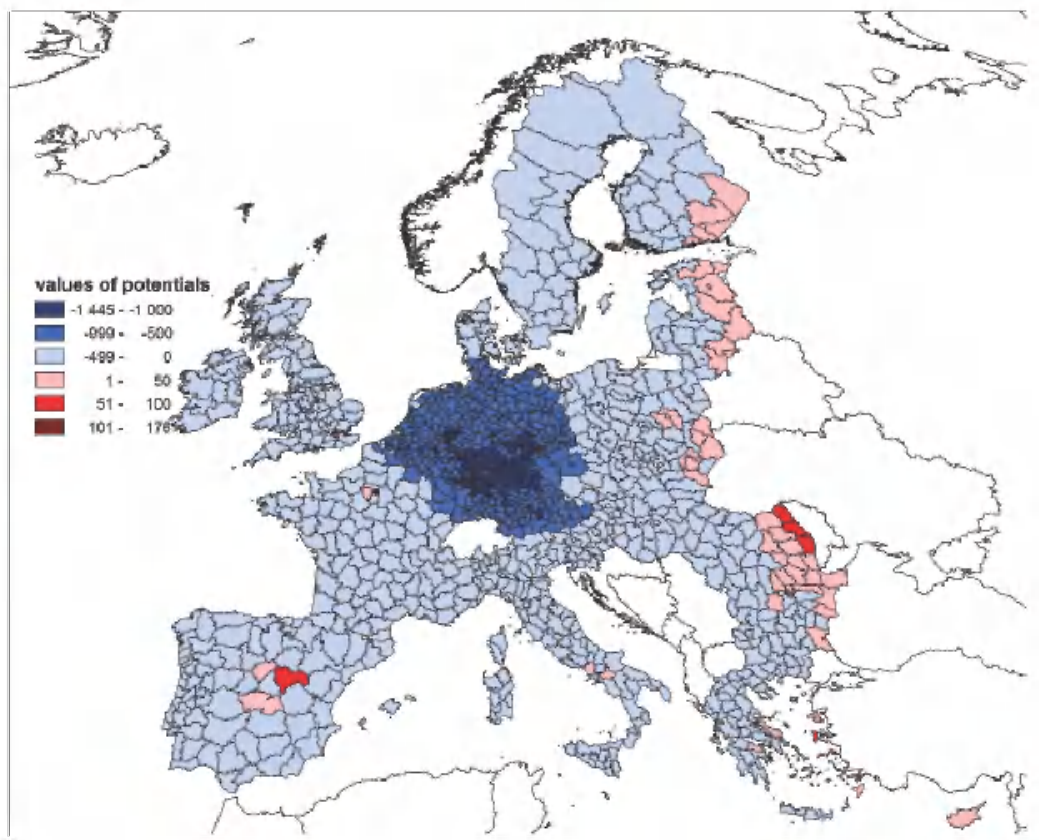

Figure 3. Role of mass distribution in population potential

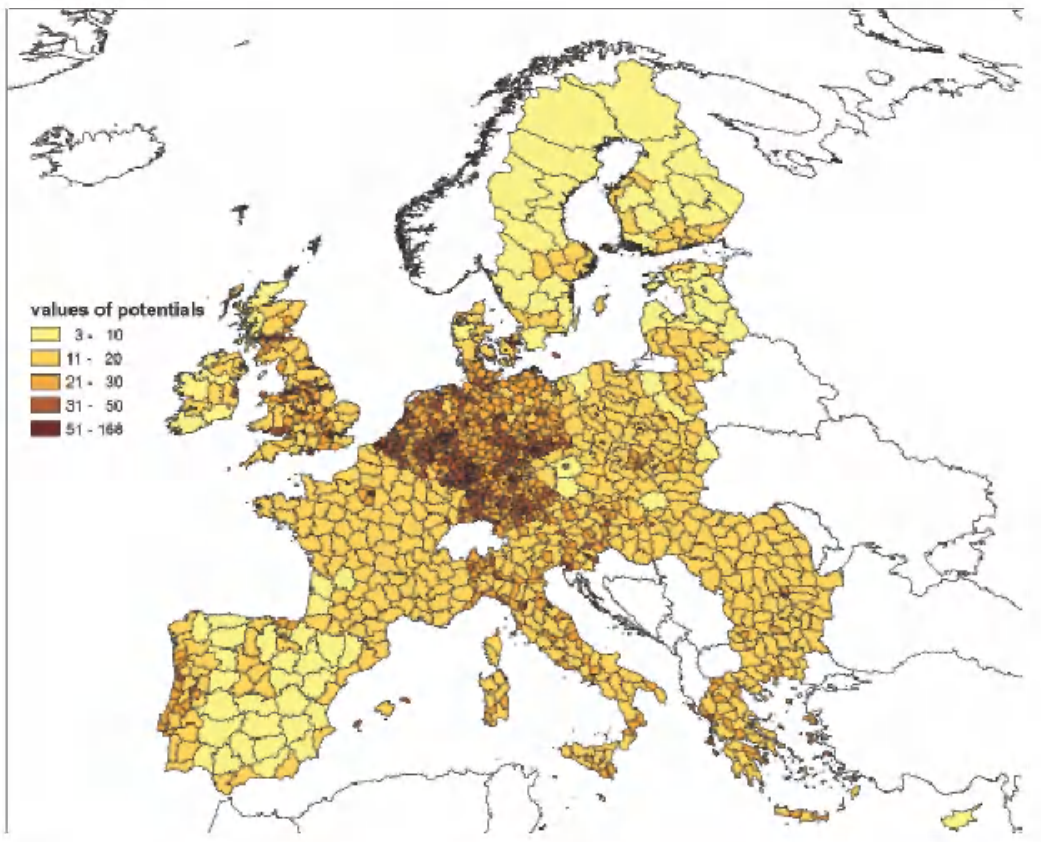

Figure 4 . Role of territory size in population potential 


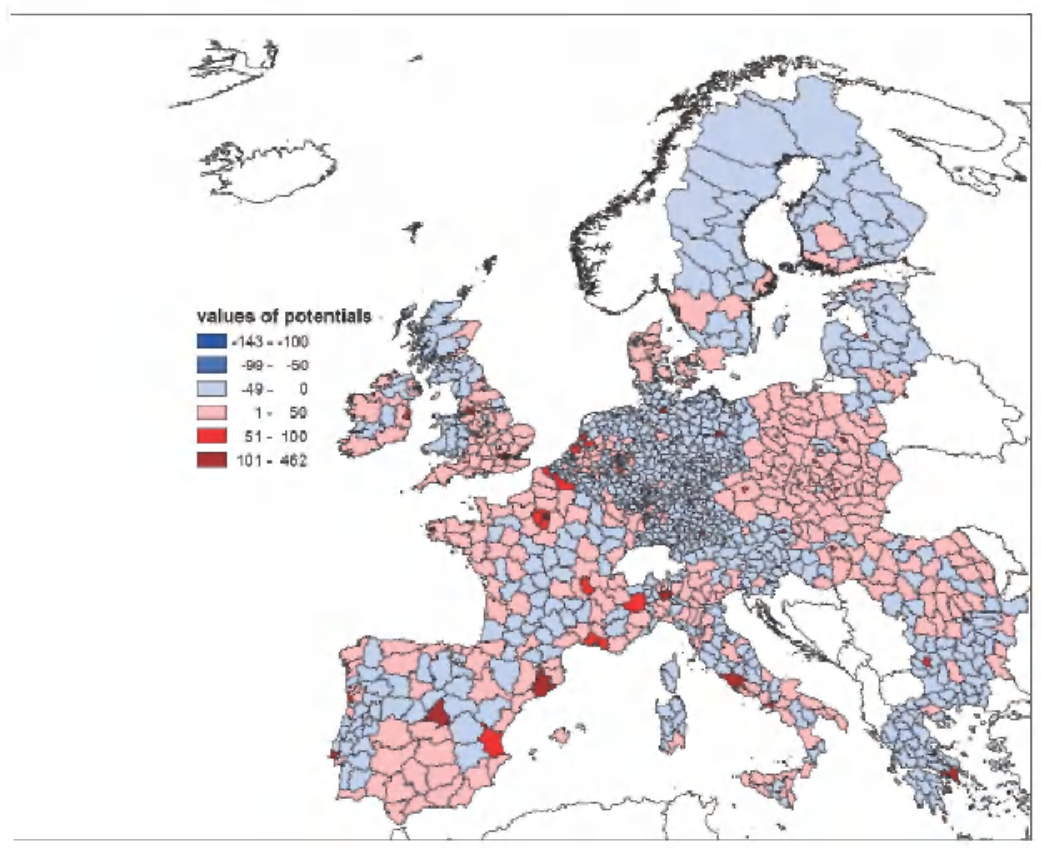

Figure 5. Role of own mass in population potential

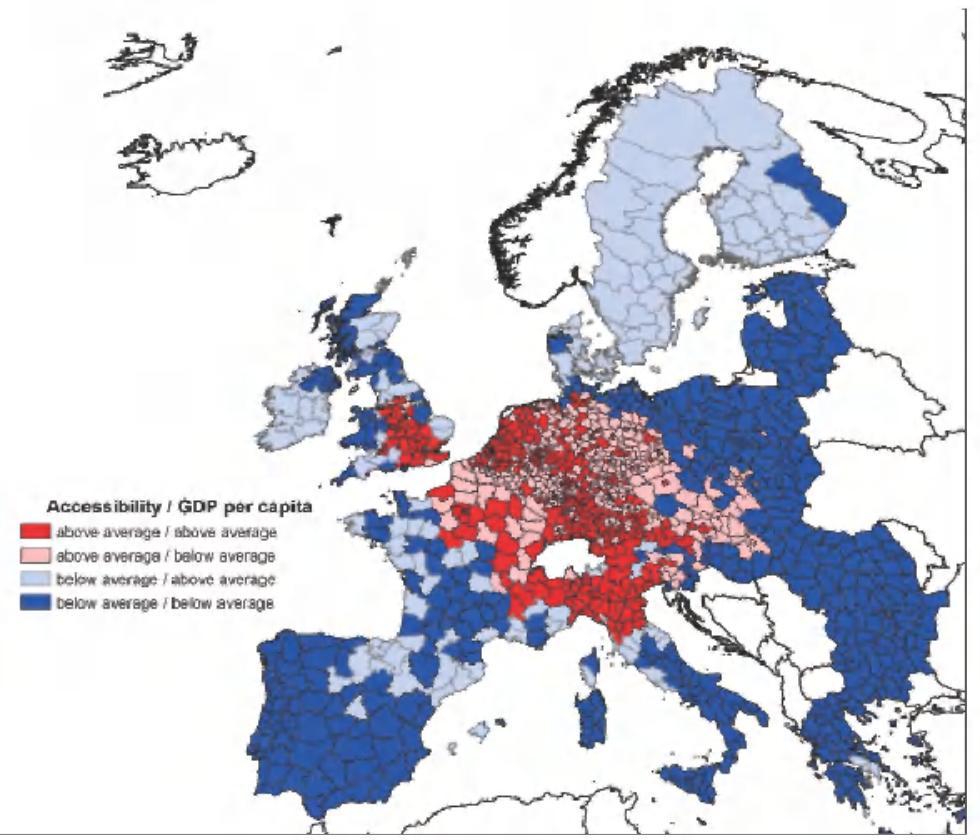

Figure 6. Comparison of accessibility and state of development of NUTS 3 regions 
age in terms of both accessibility and the level of development. Most of the Central European regions, having joined the EU in 2004, as well as many of the regions in Spain, Southern Italy and Greece can be found in this group. This is the largest of the four groups, as more than one third of the regions fall within this category.

In connection with the spatial image of development and accessibility, we can state that between the two phenomena an essential connection can be demonstrated. The group of regions that have a high level development and a high degree of accessibility, and those of low development and a low degree of accessibility, are the largest groups. These two groups together represent nearly two-thirds of all the regions.

\section{THE CONNECTION BETWEEN THE FACTORS OF DEVELOPMENT AND ACCESSIBILITY POTENTIAL}

Hereafter, we intended to examine how far the spatial distribution of territorial development can be attributed to accessibility and its components. In the interests of deeper analysis, we deemed it practical to break down GDP into several parts, which can then be easily interpreted on their own.

$\begin{aligned}\left(\frac{G D P}{\text { Population }} ;\right. & -\left(\frac{G D P}{\text { Economically actives }}\right) * \\ & *\left(\frac{\text { Economically actives }}{\text { Active aged }} ; *\right. \\ & *\left(\frac{\text { Active aged }}{\text { Population }}\right)\end{aligned}$

The GDP per capita shows the level of development of the regions, which can be broken down into factors according to the above formula. The GDP per economically active persons approaches basically the productivity of the various regions' economies; the proportion of the economically active people in the population provides an estimate of employment; and the proportion of the people who are of active age in the population can be considered to be regional resources and therefore a rough indication of age structure.

In connection with the linear accessibility potential broken down into factors and the level of development, as well as with its factors, we calculated a correlation matrix (see Table 3 ). In the matrix, italics indicate the connections which are not significant at a $5 \%$ level.

We can state that the total potential is most closely connected with the effect of spatial structure, which is then followed by mass distribution. Therefore, the basic relations of the structure of the potential are derived from the relations of the spatial structure, i.e. they are "coded" according to these relations, which is somewhat modified by the mass distribution.

On the other hand, the level of development (GDP per capita) depends primarily on productivity. Among the factors of accessibility potential, the connection is most apparent with territory size and spatial structure. The former refers to the high level of development of regions that have small areas, primarily large cities. Similarly, in terms of the spatial structure, the high level of development of the European central regions and the relative underdevelopment of the peripheries are delineated.

Among the factors of accessibility potential, the level of development is most closely connected with territory size and spatial structure. Consequently, we can state that in terms of the European spatial structure of development, accessibility can only slightly modify the productivity and employment conditions that are basically characteristic of the given region and the general spatial structural conditions that are characteristic of Europe.

On the basis of our study, we can note that within the European Union, the geographical location of the regions (the effect of structure), their central or peripheral characters are relatively closely connected 
Table 3: Correlation matrix of the factors examined

\begin{tabular}{|c|c|c|c|c|c|c|c|c|c|}
\hline Indicators & $=\frac{\bar{g}}{3}$ & 菢 & 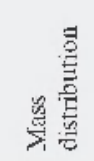 & 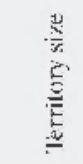 & 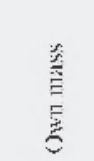 & 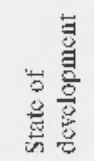 & 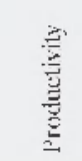 & 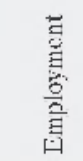 & 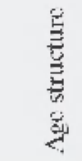 \\
\hline Total potential & 1.000 & 0.931 & -0.752 & 0.485 & -0.040 & 0.405 & 0.381 & 0.176 & -0.048 \\
\hline Spratial structure & 0.93 .31 & 1.000 & -0.939 & 0.499 & -0.253 & 0.388 & 0.351 & $0.2(i)$ & $-(1) .117$ \\
\hline Mass distribution & -0.752 & -0.939 & 1.000 & -0.468 & 0.376 & -0.348 & -0.302 & -0.310 & 0.150 \\
\hline lemritory size & 0.48 .5 & 0.499 & -0.468 & 1.000 & -0.435 & 0.444 & 0.420 & 0.159 & 0,003 \\
\hline Own mass & -0.010 & -0.253 & 0.376 & -0.435 & 1.000 & 0.010 & 0.052 & -0.150 & 0.249 \\
\hline $\begin{array}{l}\text { State of } \\
\text { dowlopment }\end{array}$ & 0.401 .5 & $0.38 x^{\circ}$ & -0.348 & 0.444 & 0.010 & 1.000 & 0.966 & $0.2 \times 2$ & $-(0.1399$ \\
\hline Produstivity & 0.381 & 0.351 & -0.302 & 0.420 & 0.052 & 0.966 & 1.000 & 0.074 & -0.195 \\
\hline Eimployment & 0.176 & 0.260 & -0.310 & 0.159 & -0.150 & 0.232 & 0.0774 & 1.000 & -0.174 \\
\hline Age struluture & -0.048 & -0.117 & 0.150 & 0,003 & 0.249 & -0.139 & -0.195 & -0.174 & 1.000 \\
\hline
\end{tabular}

with productivity and employment. It is wellknown that incomes per capita and economic growth rates are significantly higher in regions which are near the present centres of the world economy (Gallup et al. 1999). So we can state that development and economic activity within the European Union will in all likelihood concentrate in the geographical central regions in the future as well.

\section{CONCLUSIONS}

Although our study is primarily methodological in its approach, and does not focus on those issues related to a deeper analysis of the European spatial structure, our results confirm the Blue Banana spatial structural model, as well as its extension.

Our study presented a methodological experiment that sought to break down accessibility potential into factors. In our study we gave details of the spatial characteristics of each of the factors. We stated that the effect of spatial structure is the most important factor in the total potential for each region.

By examining the connection between the factors and the components of regional development, the structure of reasons for the level of development is delineated. On the basis of this, it can be stated that the level of development depends first and foremost on productivity and, among the factors of accessibility, on the size of a given territory and its spatial structure.

By comparing the spatial location of development and accessibility, it was possible to ascertain a close connection of the location of highly developed and easily accessible or underdeveloped and hardly accessible regions.

\section{ACKNOWLEDGEMENTS}

In the writing of this study Geza Toth's work was supported by the HAS Bolyai Research Scholarship.

\section{REFERENCES}

Bewley, R., Fiebig, D. G. (1988), A flexible logistic growth model with applications to telecommunications, International Journal of Forecasting, 4 (2) : 177-192.

Brunet, R. (1989), Les villes "Europeennes", La Documentation Francaise, Paris: Reclus/Datar.

Dalvi, M. Q., Martin, K. M. (1976), The measurement of accessibility: some preliminary result, Transportation, 5, (1): 17-42. 
Davidson, K. B. (1977), Accessibility in transport/ land-use modelling and assessment, Environment and Planning A. 9 (12), 1401-1416.

ESPON (2003), Transport services and networks: Territorial trends and basic supply of infrastructure for territorial cohesion. ESPON Project 1.2.1, Third interim report August 2003, <http://www.espon.eu/export/sites/default/Documents/Projects/ESPON2006Projects/ThematicProjects/TransportTrends/3. ir_1.2.1-final.pdf $>$.

ESPON (2007), Update of selected potential accessibility indicators final report, Spiekermann \& Wegener Urban and Regional Research (S\&W) RRG Spatial Planning and Geoinformation.

ESPON (2009), Territorial dynamics in Europe: Trends in accessibility, Territorial observation No. 2, <http://www.espon.eu/export/ sites/default/Documents/Publications/TerritorialObservations/TrendsInAccessibility/ to-no2.pdf $>$.

Forslund, U.M. and Johansson, B. (1995), The Malardalen-a leading region in Scandinavia and Europe?, in Cheshire, P. and Gordon, I. (eds.), Territorial competition in an integrating Europe, Aldershot: Avebury, pp. 3-27.

Fotheringham, A. S. (1982), A new set of spatialinteraction models: The theory of competing destinations, Environment and Planning $A, 15$ (1): 15-36.

Gallup, J. L., Sachs, J D., Mellinger, A. D. (1999), Geography and economic development, in:Annual World Bank Conference on Development Economics 1998 (April). The World Bank, Washington, DC, pp. 127-178., Reprinted in International Regional Science Review, 22(2): 179-232.

Geertman, S.C.M. and van Eck, J.R.R. (1995), GIS and models of accessibility potential: an application in planning, International Journal of Geographical Information Systems 9 (1): $67-80$.

Geurs, K.T. and van Eck, R. JR (2001), Accessibility measures: review and applications. Evaluation of accessibility impacts of land-use transportation scenarios, and related social and economic impact, Report no. 408505006 , $<$ http://www.mnp.n1/bibliotheek/rapporten/408505006.pdf>, 265 p.
Geurs, K.T. and Wee, B. (2004), Accessibility evaluation of land-use and transport strategies: review and research directions, Journal of Transport Geography 12 (2): 127-140.

Gutierrez, J. (2001), Location, economic potential and daily accessibility: an analysis of the accessibility impact of the high-speed line Madrid-Barcelona-French border, Journal of Transport Geography 9 (4): 229-242.

Guy, C. M. (1983), The assessment of access to local shopping opportunities: a comparison of accessibility measures, Environment and Planning B: Planning and Design. 10 (2): 219-238.

Hansen, W.G. (1959), How accessibility shapes land-use, Joumal of the American Institute of Planners, 25 (2): 73-76.

Harris, C. D. (1954), The market as a factor in localisation of industry in United States, Annals of the Association of American Geographers, 44 (4): $315-348$.

Hilbers, H. D. and Veroen, E. J. (1993), Het beoordelen van de bereikbaarheid van lokaties. Definiering, maatstaven, toepassingen beleidsimplicaties, INRO-VVG 1993-09, TNO Inro, Delft.

Ingram, D. R. (1971), The concept of accessibility: A search for an operational form, Regional Studies, 5 (2): 101-105.

Joseph, A.E. and Bantock, PR. (1982), Measuring potential physical accessibility to general practitioners in rural areas: a method and case study, Social Science and Medicine, 16 (1): 85-90.

Keeble, D, Offord, J., Walker, S. (1988), Peripheral regions in a community of twelve, Office for Official Publications of the European Communities, Brussels/Luxemburg.

Keeble, D., Owens, PL., Thompson, C. (1982), Regional accessibility and economic potential in the European Community, Regional Stud$i e s, 16: 419-432$.

Kincses, A. and Toth, G. (2011), Potencialmodellek geometriaja [Geometry of potential models], Területi Statisztika [Spatial statistics], 14 (1): 23-37.

Knox, PL. (1978), The intraurban ecology of primary medical care: patterns of accessibility and their policy implications, Environment and Planning $A$ 10 (4): 415-435. 
Kunzmann, K. R. (1992), Zur Entwicklung der Stadtsysteme in Europa, in Stiglbauer, K. (ed.), Mitteilungen der. Österreichischen geographischen Gesellschaft. Band 134, Wien. pp. 25-50.

Linneker, B. J. and Spence, N. A. (1992), An accessibility analysis of the impact of the M25 London Orbital Motorway in Britain, Regional Studies, 26 (1): 31-47.

Lukermann, F. and Porter, PW. (1960), Gravity and potential models in economic geography, Annals of the Association of American Geographers, 50 (4): 493-504.

Martin, K. M. and Dalvi, M. Q. (1976), The comparison of accessibility by public and private transport, Traffic Engineering and Control, 17 (12): 509-513.

Nitsch, W. (2000). National border and international trade: Evidence from the European Union., Canadian Journal of Economics, 22: 1091-1105.

Puga, D. (2002), European regional policies in light of recent location theories, Journal of Economic Geography, 2(4): 373-406.

Redding, S.J. and Venables, A.J. (2001), Economic geography and international inequality, Manuscript, London School of Economics.

Rich, D.C. (1978), Population potential, potential transportation cost and industrial location, Area, 10: 222-226.

Rich, D.C. (1980), Potential models in human geography, Concepts Geoabstracts Catmog (26), Norwich, University of East Anglia.

Schürmann, C., Spiekermann, K., Wegener, M. (1997), Accessibility indicators, Berichte aus dem Institüt für Raumplanung 39, Dortmund, IRPUD.

Simma, A., Vrtic, M., Axhausen, K.W (2001), Interactions of travel behaviour, accessibility and personal characteristics: The Case of Upper. Austria, Paper presented at European Transport Conference, Cambridge, September 2001.

Smith, D.M. and Gibb, R.A. (1993), The regional impact of Channel Tunnel. A return to potential analysis. Geoforumi, 24.(2): 183-192.

Song, S. (1996), Some tests of alternative accessibility measures: A population density approach, Land Economics, 72 (4): 474-482.

Spence, N. A. and Linneker, B. J. (1994), Evolution of the motorway network and changing levels of accessibility in Great Britain, Journal of Transport Geography, 2 (4): 247-264.

Spiekermann, K. and Neubauer, J. (2002), European accessibility and peripherality: Concepts, models and indicators, Nordregio Working Paper, 9, p. 43.

Spiekermann, K. and Wegener, M. (2006), Accessibility and spatial development in Europe, Scienze Regionali, 5 (2): 15-46, < http://www. spiekermann-wegener.de/pub/pdf/KSMW_ Scienze_Regionali.pdf $>$.

Stewart, J.Q. (1947), Empirical mathematical rules concerning the distribution and equilibrium of population, Geography Review, 37 (3): 461-485.

Tagai, G. (2007), A potencialmodell erenyei es hatranyai a tarsadalomkutatasban [Virtues and limits of potential model), Ter es Társadalom [Space and Society], 21 (1): 145-158.

Toth, G. and Kincses, A. (2007), Elerhetosegi modellek [Accessibility models], Ter es Társadalom [Space and Society], 21 (3): 51-87.

Van Wee, B., Hagoort, M., Annema, J.A. (2001), Accessibility measures with competition, Journal of Transport Geography, 9 (3): 199-208.

Vickerman, R.W. (1974), Accessibility, attraction, and potential: A review of some concepts and their use in determining mobility, Environment and Planning A, 6 (6): 675-691.

Weibull, J.W. (1976), An axiomatic approach to the measurement of accessibility, Regional Science and Urban Economics, 6 (4): 357-379.

Wilson, A. G. (1971), A family of spatial interaction models, and associated developments, Environment and Planning A, 3. (1): 1-32.

Paper first received: June 2011

In final form: November 2011 